International Journal of Advanced Studies in Humanities and Social Science (IJASHSS)

Available online at http://www.ijashss.com

Volume 8, Issue 1 (2019) pp. 119-124

Original Article

\title{
The Effect of Earthquake on Youth Tendency to Artificial Narcotics Consumption in Bam Township
}

\section{Hossain Sharifian*, Mahmoud Roholamini, Mohammad Mehdi Mossavi}

Department of Law, Islamic Azad University, Science and Research Branch of Kerman, Iran

*Corresponding Author E-mail: mojdaria45@yahoo.com

Received: 24 October 2018, Revised: 05 December 2018, Accepted: 20 December 2018

\begin{abstract}
This research is aimed to study the effect of earthquake on changing the pattern of traditional narcotics consumption into artificial narcotics in Volunteers of addiction abandonment in Green Houses. The present research is a discretional study. The subjects of research include 150 males who were going to abandon the Consumption of artificial narcotics and had referred to the centers of Green House. By observing them, the test was evaluated by distributing questionnaires. Data analysis was performed by using the methods of descriptive statistics ( chi -2 test) Findings the abundance, cheapness, easy availability to materials, preferred Communication, The relationship to bad friends, addict parents, Low Self - Confidence are meaningfully related to youth tendency to artificial narcotics consumption after earthquake. Request of youth Volunteers from Green Houses to a bonbon addiction should be considered as an interaction between individual psychology and effect of cultural abnormality in Society. Social abnormality after earthquake Caused youth tendency to use narcotics and consequently they have changed their pattern into artificial narcotics Consumption.
\end{abstract}

Keywords: Artificial Narcotics, Addiction, Addict, Narcotics, Tolerance.

\section{Introduction}

After earthquake in Bam Township, the consumption of artificial narcotics became suddenly common among youth, and changed into important Social problem, it was developed by immigrate the families and youth of other cities to Bam They had been coming to Bam to Find a Job and Work.

Regarding to those artificial narcotics is a new phenomenon, recognizing their danger requires information and Continual advertisements among Society youth. Unfortunately, tendency of poor and rich youth to use narcotics has become a crisis. Dependence on narcotics is called "the largest nuisance" because the Losses resulting from it cause destroying many values and cultural abnormality and endanger society's health. Every day, the number of people depending on materials increases. The weakness of Social organizations in fighting to this new phenomenon has resulted in decreasing addiction ago to 13 years old. The highest consumption is related to 13029 years old. 
Communicating with bad friends, addict parents, materials abundance and their easy availability and Low self - Confidence among youth in Bam Township has affected on youth tendency to these narcotics.

Until now, in national and international Level, may researches have been performed about addiction to traditional narcotics? The results of previous researches are about the ideas of genetic scientists, and functionalism views and interactions are less mentioned. Appearing artificial narcotics in the beginning of 1970 became suddenly a global problem and consequently technologically progressing of these materials in the form of tablets, ampoules and different forms in the world and Iran among youth became common, It's clear that researches about youth tendency to use artificial narcotics are Less performed, while today, we see fourth social crisis after nuclear, environmental and population crisis.

Increasing use and distribution of artificial narcotics is So that in future they will replace traditional narcotics. In this paper, the effect of earthquake on youth tendency to use artificial narcotics and also the destructive effects exerting on surviving people in Bam Township.

\section{Method of Research}

The basis of research is a field method depending on discretional statistics, because it evaluates The Correctness of method. The purpose of selecting this research method is to make the researcher able to find the way of study and easily achieve the answers to questionnaires.

We have mentioned the research method, statistical Society, Sample Volume, Sampling method, the tools to collect data questionnaires and applied statistical methods. In the part of descriptive statistics, the table of abundance distribution and Chi -2 test are used.

\section{Volume and Statistical Society}

The Statistical Society in this research includes 150 males, who are randomly selected from abusers of artificial narcotics, and the questionnaires were distributed among all of them and its results are reported in hypothesis description.

\section{Sampling Method}

In measurement researches, the people are usually selected randomly and by questionnaire, we report the information's of 150 male group.

The tools and methods of collecting information: The methods of date collection in this research include:

Observation, questionnaire and Library study narrative: allowable.

The test narrative is aimed to find that whether a tool to measure Considered cases is suitable or not.

\section{Dynamism: Validation}

The dynamism of this questionnaire by using coefficient of kronbach alpha is estimated \% 90.

\section{The Method of Data Analysis}

This article hypothesis in the part of discretional statistics are provided by using the tables of abundance distribution. All of statistical calculations are performed by using SPSS software.

\section{Description and Analysis}

Regarding to that the problem of research is effect of earthquake on youth tendency to use artificial narcotics in Bam Township, the date and analysis should have a regular method. It's clear that after 2003 earthquake in Bam Township, a cultural interaction occurred and changing 
the pattern of traditional narcotics consumption to artificial narcotics was appeared. To analyze data, the guess of researcher is tested and hypothesis correctness is studied. In order to achieve required data, three hypotheses were designed in addition to observations and questionnaires. After data collection the data analysis was performed to evaluate the hypothesis of material abundance and cheapness and their easy availability that they have been effective on youth tendency to use artificial narcotics. Chi - 2 test is also used.

Does communication with bad friends or addict parents Cause increase in artificial narcotics use?

Regarding to data analysis, 66 percent of Causes of tendency to narcotics are Communication with bad friends, 44 Percent is related to addict parents.

Table 1. Data analysis

\begin{tabular}{ccc}
\hline percent & Abundance & Communication \\
\hline 66 & 100 & Bad Friends \\
34 & 50 & Parents \\
100 & 150 & group \\
\hline
\end{tabular}

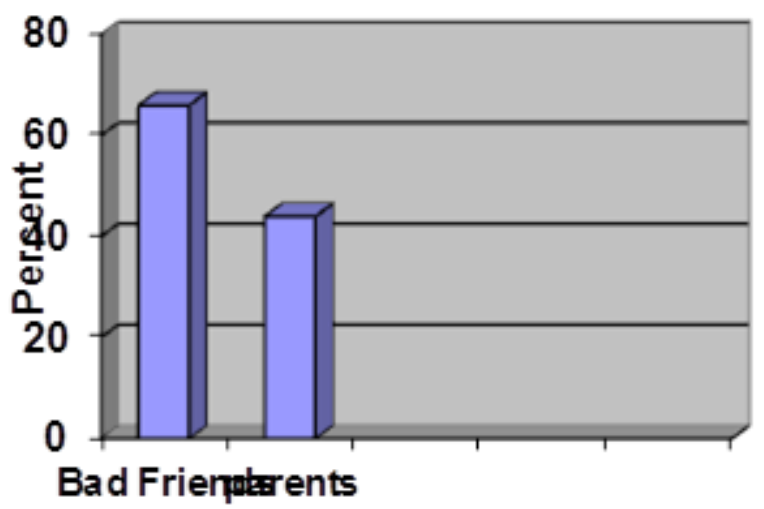

\section{Inferred Statistics}

Hypothesis 1: Is there any meaningful relationship between youth Communication with bad friends and parents and begin to use narcotics?

Ho: The effects of friends and addict parents on addiction are equal.

H1: The effect of addict parents and friends on addiction is not equal.
To study this hypothesis, we use Chi - 2 test.

Regarding to that sample people have mentioned the Communication with friends and addict parents, we want to examine whether the effect of bad parents is more or not?

Table 2. Chi 2 test

\begin{tabular}{cccc}
\hline Difference & Expected & Observed & Communication \\
\hline+34 & -66 & 100 & Friends \\
-10 & 50 & 40 & Addict Parents \\
& & 100 & Total \\
Chi-Square $=28.000$ & $\mathrm{df}=2$ & Asymp. Sig. $=0.000$ \\
\hline
\end{tabular}


The results of descriptive statistics are shown with regard to observed abundance and expected abundance. According to this table, the statistical value of chi -2 is two times 28, and freedom degree is 2 and its meaningful Level is less than \%5. Then Ho in the Level of $\% 5$ is rejected and indicates that Compared to other groups, bad friends had the highest effect on addiction.
The abundance distribution of sample people based on Lack of Self - Confidence Causes tendency to use artificial narcotics. Regarding to date analysis, \%58 of respondent people had no enough Selfconfidence and \%42 of people had self Confidence.

Table 3. Self - Confidence

\begin{tabular}{ccc}
\hline percent & Abundance & Lack of Self- Confidence \\
\hline 58 & 87 & Yes \\
42 & 63 & No \\
100 & 150 & Total \\
\hline
\end{tabular}

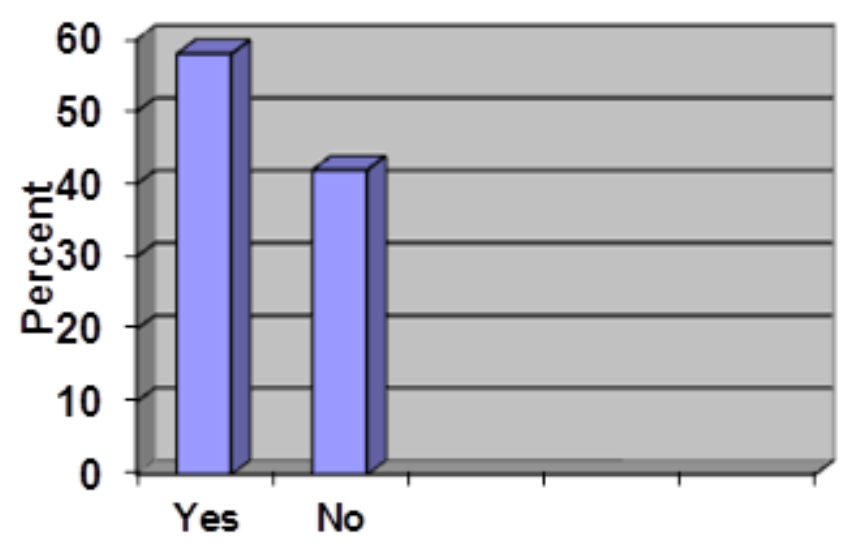

Hypothesis 2: Lack of youths Selfconfidence is meaningfully related to their tendency to use narcotics and their addiction:

To test this hypothesis, the following question is posed:
Does Lack of Self - Confidence cause increase in using artificial narcotics?

H0: The Lack of Self - Confidence does not effect on peoples addiction

H1: The Lack of Self - Confidence effect on people's addiction.

Table 4. Confidence effect

\begin{tabular}{cccc}
\hline Difference & Expected & Observed & Lack of Self-Confidence \\
\hline+15 & 75 & 90 & Yes \\
-15 & 75 & 60 & No \\
& & 150 & Total \\
Chi-Square $=6.000$ & $\mathrm{df}=1$ & Asymp. Sig. $=0.014$ \\
\hline
\end{tabular}

The results of table 4 show that among Sample people 90 lacked self - Confidence. With regard to table, the Volume of Chi - 2 is 6 and freedom degree is 1 and its meaningful Level is less than \%5. Then Ho is rejected. So Lack of Self - confidence by 
youth is effective on youth tendency to use artificial narcotics.

Was the reason of tendency to use artificial narcotics in Bam easy availability to these materials?
With regard to data analysis, the respondent people included: $68 / 6$ percent of 18- 29 years old; 20 percent of $30-40$ years old. The most answers were related to ages of 18 to 29 .

Table 5. Respondent people

\begin{tabular}{ccc}
\hline Percent & Abundance & Availability \\
\hline $66 / 5$ & 100 & Youth \\
34 & 50 & Aged People \\
100 & 150 & Total \\
\hline
\end{tabular}

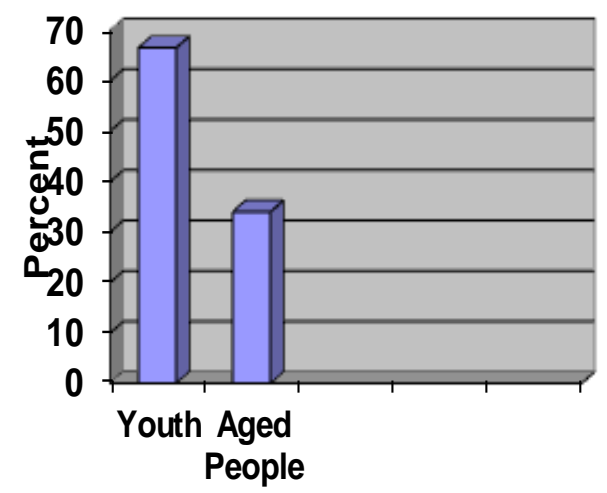

Hypothesis 3: easy availability to artificial narcotics is meaningfully related to youth's tendency to use these materials:

To test this hypothesis, we pose the following question:

Is easy availability to artificial narcotics related to increase in these materials consumption?

Table 6. Availability test

\begin{tabular}{cccc}
\hline Difference & Expected & Availability & \\
\hline+25 & 75.0 & 100 & Yes \\
-25 & 75.0 & 50 & No \\
& & 150 & Total \\
Chi-Square $=16 / 667$ & $\mathrm{df}=1$ & Asymp. Sig.= 0.000 \\
\hline \multicolumn{4}{c}{ (Setoudeh , Hedayat; 2004) }
\end{tabular}

\section{Conclusion}

As it's clear from the results of methodology, the main factors effecting on youth's tendency to use artificial narcotics include communication with bad friends
H0: easy availability to artificial narcotics doesn't effect on addiction.

H1: Easy availability to artificial narcotics effect on addiction.

HO mentions that easy availability to artificial narcotics doesn't effect on youth addiction. 
isn't an individual Selection, but its related to social characteristics of each tribe. And race that exhibits disorders and deviated ideas of people. It's in agreement with behaviorism and Learning theories. The more is the relationships to bad peoples, the more is number of youth who learn to abuse.

The difference between reasonable and unreasonable can't be recognized by the person who is predisposed to abuse. Then he or she becomes addict and because the behavior of dependence on narcotics is learned by persons, it's learned from addict parents and friends. $90 \%$ of the participating persons, have primarily experienced to use materials with their friends, and easy availability to narcotics motivated them to buy and use them.

UN doubly, Low self - Confidence by youth is one of the main factors effecting on abuse.

If schools, Families and other Social organizations prevent youth to Communicate with unreasonable friends and make them farther from bad environments, the will have less

How to cite this article: Hossain Sharifian, Mahmoud Roholamini, Mohammad Mehdi Mossavi, The Effect of Earthquake on Youth Tendency to Artificial Narcotics Consumption in Bam Township. International Journal of Advanced Studies in Humanities and Social Science, 2019, 8(1), 120-125. http://www.ijashssjournal.com/article 84114.html experience to use narcotics. To decrease youth's tendency of Bam Township, Some recommendations are provided. Certainly, the prevention is better than treatment. Here, the family is very important.

The families can Control the relations of their youth, and Can Play the best role to decrease undesirable behaviors.

\section{References}

Setudeh H. (2011). Social pathology, publication avay nor.

Salehi I. (1993). Chains of addiction,publication nor.

Kamal A. (2011). Directory Addicted Patients,medical university.

Mahiar A. and nohi S. (2009). Encyclopedia of addiction,publication arjomand.

Rafiei H. (2000). Encyclopedia of addiction,publication danjeh. 